\title{
UN VIAJE A TRAVÉS DE LOS POEMAS: ACERCAMIENTO AL TRATAMIENTO ESPACIAL EN LA POESÍA DE ANTONIO COLINAS ${ }^{1}$
}

\author{
A JOURNEY THROUGH POEMS: AN APROACH TO \\ THE TREATMENT OF SPACE IN ANTONIO COLINAS' POETRY
}

Clara I. MARTÍNEZ CANTóN

UNED

cimartinez@flog.uned.es

\section{Ana RODRÍGUEZ PÉREZ}

UNED

ana.rodriguez.perz@gmail.com

Resumen: Antonio Colinas ha trazado una sólida trayectoria poética que ha sido reconocida con múltiples premios. Este recorrido poético no está, sin embargo, limitado a una geografía meramente ficcional, sino que bebe y respira su propia experiencia personal. Así, sus composiciones son una invitación al viaje y nos arrastran por parte de la geografía europea, entre los que destacan tres lugares fundamentales de su vida: León, Italia e Ibiza. Este trabajo estudia y presenta la geografía de las obras colinianas a través de herramientas de geolocalización, mostrando y aprovechando así las posibilidades de las Humanidades Digitales al estudio de la poesía.

Palabras clave: Antonio Colinas, poesía, Humanidades Digitales, geolocalización, geografía literaria.

Abstract: Antonio Colinas has already a solid poetic career that has been recognized with multiple awards. His poetic work is a journey not limited to a merely fictional geography, but rather it is inspired in his own personal experience. Thus, his poems are an invitation to travel, and bring the

\footnotetext{
${ }^{1}$ Este trabajo ha sido apoyado por Pelagios Commons Resource Development Grants con título «Mediaeval Iberia through Pelagios Commons» dirigido como investigadora principal por Gimena del Rio (CONICET, Argentina). Este trabajo se enmarca dentro del proyecto de investigación Starting Grant Poetry Standardization and Linked Open Data: POSTDATA (ERC-2015-STG-679528), financiado por el European Research Council (ERC) bajo el programa: European Union's Horizon 2020 research and innovation programme, dirigido como Investigador Principal por la profesora Elena GonzálezBlanco.
} 
268 Tropelías. Revista de Teoría de la Literatura y Literatura Comparada, 30 (2018)

Clara I. Martínez Cantón y Ana Rodríguez Pérez

reader through the European geography, with special relevance of three spaces: Leon, Italy and Ibiza. This work studies and presents the geography of the Colinian poems through geolocation tools, showing and taking advantage of the possibilities of Digital Humanities to the study of poetry.

Keywords: Antonio Colinas, poetry, Digital Humanities, geolocation, literary geography. 


\section{$\mathbf{0}$}

\section{Introducción}

Antonio Colinas (La Bañeza, 1946) se ha convertido en un referente de nuestra literatura, especialmente por su labor como poeta. Escritor polifacético, su habilidad con la pluma le ha llevado no solo a la poesía, sino que también al ensayo, la novela, la traducción y la crítica literaria. De hecho, su larga trayectoria se ha visto reconocida con varios premios, incluido el Premio Nacional de la Crítica (1975), el Premio Nacional de Literatura en 1982, el Premio de las Letras de Castilla y León (1999) y el reciente premio Reina Sofía de Poesía Iberoamericana en 2016. Particularmente, el bañezano se ha labrado un camino en el mundo literario a través de un tratamiento muy personal de la poesía, alejado de las tendencias predominantes y las modas pasajeras, así como centrado en la búsqueda de un lenguaje propio, de una poética donde pueda filtrar su experiencia personal para extraer sentencias de carácter universal.

Muchas han sido las aproximaciones al estudio de su obra poética, tanto desde el campo de la métrica (Martínez Cantón, 2011, 2012) como desde el análisis de la transtextualidad (Tadoun, 2009), la traducción (Calleja Medel, 2003), sus ensayos (Badía Fumaz, 2016a), su poética (Badía Fumaz, 2016b) o los distintos ejes temáticos como pintura (Martínez Fernández, 2008; Martínez Fernández y Martínez Cantón, 2017), música (Martínez Cantón, 2014), etc. entre otras muchas. Las diferentes aportaciones han ido enriqueciendo la lectura y la comprensión de la obra coliniana, pero aún queda espacio para nuevas aportaciones. Así, con el presente trabajo, buscamos realizar un estudio de la particular dinámica espacial dentro de la poética de Antonio Colinas. Sus poemas recorren parte de la geografía europea, especialmente a través de la transfiguración de tres lugares fundamentales de su vida: León, Italia e Ibiza. Contamos ya con ciertos acercamientos al tratamiento del espacio en la introducción de En la luz respirada por Martínez Fernández (2004) o en «Parte segunda: el diseño espacial imaginario» dentro de la tesis de Agustín Fernández (2011), si bien aquí se pretende ofrecer una nueva aproximación desde el campo de las Humanidades Digitales (en adelante HD), centrándonos en la expansión del pensamiento del poeta a través del espacio geográfico y cómo este ha ido evolucionando a lo largo de su obra. Las posibilidades que nos ofrece este nuevo enfoque son múltiples: geolocalización, visualización de datos, navegación por poemas, etc., con lo que además de ofrecer un estudio del tema se ofrece una herramienta para adentrarnos en la obra del autor de un modo diferente.

\section{Metodología y estado de la cuestión}

Pero, ¿qué entendemos por Humanidades Digitales? A grandes rasgos, se trata de una etiqueta generalista para englobar la convergencia de los estudios humanísticos con el tratamiento informático de los datos. Esta amplia definición implica una gran imprecisión. Es interesante cómo Galina sortea este problema de definición de las HD al centrarse en las consecuencias de su aplicación: la apertura 
de un nuevo campo de investigación. Así, el empleo de formatos digitales supone «nuevas perspectivas al conocimiento en las disciplinas humanísticas», puesto que aportan «novedosas herramientas para aprovechar los recursos utilizados en la investigación» (Galina Russell, 2011: 8). De manera muy breve y sin pretensión de hacer una definición exhaustiva, las Humanidades Digitales se configuran hoy en día como un campo interdisciplinar en el que las tecnologías digitales abren nuevas teorías, métodos, actividades y objetos de investigación.

Dentro del ámbito literario hispano, las aportaciones literarias desde las HD han sido enfocadas especialmente hacia la creación de bancos de datos como pueden ser la Biblioteca Cervantes Virtual ${ }^{2}$, $\mathrm{ReMetCa}^{3}$ (Repertorio métrico digital de la poesía medieval castellana) o Bieses ${ }^{4}$ (Bibliografía de escritoras españolas), que permiten documentar, agrupar y difundir información que facilite la labor de los investigadores. Otro tipo de proyectos donde confluyen la Literatura y la Tecnología hacia nuevos campos de investigación y nuevas metodologías son los enfocados hacia el procesamiento del lenguaje natural u otros datos, dando lugar a estudios de estilometría siguiendo la metodología del Distant Reading (Moretti).

En relación con nuestro trabajo, queremos destacar las herramientas de geolocalización que permiten establecer asociaciones entre la literatura y la cartografía. Los Sistema de Información Geográfica (SIG) son, dicho de una manera muy simplificada, softwares que manejan la información de lugares y de mapas a través de bases de datos, es decir, ofrecen la posibilidad de codificar datos espaciales y localizarlos en un mapa. Esto abre nuevas puertas a la enseñanza de la literatura con aplicaciones didácticas como son las creaciones de rutas literarias, pero también a los estudios literarios con la posibilidad de la implementación de nuevas metodologías y herramientas al estudio de periodos, autores u obras concretas.

Como indica Piatti, «Die Idee, die räumliche Dimension von literarischen Werken in Karten umzusetzen, ist beileibe nicht neu, sie hat vielmehr eine erstaunlich lange Tradition» ${ }^{5}$ (2012). Ejemplo de ello se encuentra en la inserción de mapas tanto ficticios como reales en obras como El señor de los anillos de J.R.R. Tolkien o Utopía de Thomas More. Estos ejemplos responden a la tradicional asociación del espacio a los textos narrativos pero, como veremos, también puede acoger una gran representación dentro del género lírico. Podemos recordar los poemas áureos en donde aparecen numerosas loas a ciudades o ríos. Por ello, la aplicación de las herramientas SIG no supone algo estrafalario o innecesario, sino que favorece la investigación interdisciplinar de la Literatura y de la Cartografía. De hecho, ya existen proyectos literarios muy interesantes como la reciente aparición de atlas literarios. A Literature Atlas of Europe de la Escuela Politécnica Federal de Zúrich, por ejemplo, es un atlas cuyo objetivo es geolocalizar los espacios literarios dentro de Europa. En la web del

\footnotetext{
${ }^{2}$ www.cervantesvirtual.com, consultado el 22 de diciembre de 2017.

${ }_{3}^{3}$ www.retmeca.uned.es/index.php?lang=es, consultado el 22 de diciembre de 2017.

4 www.bieses.net, consultado el 22 de diciembre de 2017.

5 «La idea de establecer la dimensión espacial de las obras literarias en mapas, no es nuevo; más bien tiene una tradición sorprendentemente larga» (traducción propia).
} 
proyecto establecen que su intención es responder a dos preguntas: «Where is literature set and why there $\gg^{6}(2017)$.

Dentro de los proyectos de geolocalización literaria, las herramientas ofrecidas son numerosas y de fácil acceso. Existen numerosos proyectos de gran envergadura entorno a la geolocalización literaria, entre los que cabe destacar Pelagios, que comenzó como un proyecto dedicado a la reconstrucción del mundo antiguo mediante datos enlazados geográficos, elaborando mapas en los que datos geoespaciales históricos se relacionaban con contenidos en otras fuentes de recursos en línea ${ }^{7}$. Actualmente, Pelagios ha dejado de ser un proyecto para convertirse en una comunidad que va creciendo gracias a diversas iniciativas y micro proyectos integrados. Destacamos, por cercano y por centrarse en el ámbito hispánico, el proyecto Mediaeval Iberia through Pelagios Commons ${ }^{8}$ realizado por los investigadores del LINHD (Laboratorio de Innovación en Humanidades Digitales) de la UNED. El objetivo de este último proyecto es identificar los topónimos medievales de la península incluidos en los documentos de Alfonso X el Sabio recogidos del Hispanic Seminary of Medieval Studies (HSMS). Para ello, los textos son recogidos en Recogito, una herramienta que permite aplicar etiquetas de referencias geográficas a textos de diferentes épocas a través de gazetteers, concretamente se emplea el Pleiades Gazetteer de Pelagios. Posteriormente, estas etiquetas se pueden trasladar a Pelagios para poder mapear las referencias etiquetadas en el texto y, así, aportar una geografía fácilmente visible de la realidad de la época medieval representada en los textos.

Otra aplicación interesante es TimeMapper, una herramienta que permite trazar líneas del tiempo a la vez que referenciar lugares concretos en un GoogleMaps. Esta herramienta será la que emplearemos en el presente trabajo. Su principal cualidad radica en que es la única herramienta de geolocalización que facilita la producción de mapas animados de vectores, automática y directamente, a partir de datos espacio-temporales hacia un formato apropiado para su difusión en internet (Köbben, Becker, y Blok, 2010). En relación con la literatura, TimeMapper puede aplicarse para plasmar coordenadas espacio-temporales que hayan marcado la producción de autores o de movimientos literarios, así como realizar un seguimiento de las rutas de los libros de viajes y aventuras. De esta forma, se consigue una clara visualización de la evolución espacio-temporal del tema tratado y se favorece la consecución de su análisis y de las conclusiones. Un ejemplo de su aplicación dentro del ámbito literario es la creación de líneas del tiempo georreferenciadas en un mapa como el proyecto «Cervantes y los libros del Siglo de Oro» ${ }^{9}$. Este proyecto ha sido llevado a cabo por la Biblioteca de Castilla-La Mancha como apoyo a la exposición titulada «Cervantes y los libros del Siglo de Oro en

\footnotetext{
${ }^{6}$ «¿En dónde se localiza la literatura y por qué?» (traducción propia); en http://www.literaturatlas.eu/en/, consultado el 22 de diciembre de 2017.

${ }^{7}$ Para más información se puede consultar el apartado de publicaciones de su sitio web: http://commons.pelagios.org/ publications/, consultado el 22 de diciembre de 2017.

${ }^{8}$ Más información sobre el proyecto se puede encontrar en http://commons.pelagios.org/2016/mediaeval-iberia-throughpelagios-commons/, consultado el 22 de diciembre de 2017.

${ }^{9} \mathrm{Se}$ puede navegar el proyecto desde http://timemapper.okfnlabs.org/biblioclm/cervantes-y-los-libros-del-siglo-de-oro, consultado el 22 de diciembre de 2017.
} 
la Colección Borbón-Lorenzana» ${ }^{10}$. Así, esta línea del tiempo permite realizar un seguimiento espacial y cronológico de las ciudades que marcaron al escritor, así como aquellas en las que se desarrollan sus obras más representativas como El Quijote. Todo ello apoyado en imágenes y estampas de las ediciones de sus obras.

\section{1. Metodología}

Como ya hemos mencionado, la concreción geográfica ha sido algo fundamental para la literatura pero, generalmente, se ha limitado al género narrativo. Por ello, con este trabajo queremos ampliar este enfoque al género lírico, a la vez que demostramos la utilidad de las herramientas de geolocalización para su estudio. La obra poética de Antonio Colinas representa un magnífico ejemplo de la importancia que puede alcanzar el espacio en las composiciones poéticas. Para Agustín Fernández, la significación del espacio es clave para entender la obra coliniana puesto que este «invita a la profundización y al viaje, crea una atmósfera espiritual y reelabora las fantasías del poeta: la isla, Petavonium, la casa, el mar, el bosque...» (Agustín Fernández, 2011: 16). Todos estos espacios nacen de la propia experiencia vital del poeta: los respira y los exhala en su poesía, los traslada de la realidad filtrándolos a través de su mente para expresar su propia intimidad.

Así, nuestro objetivo se ciñe a un análisis del tratamiento del espacio en la obra poética de Antonio Colinas con el apoyo de una herramienta de geolocalización: TimeMapper. Esta aplicación nos permitirá no solo organizar su poesía a través de coordenadas espacio-temporales, sino que también nos abrirá una perspectiva más visual, didáctica y dinámica al estudio de su poesía. Sin embargo, como afirma Martí:

El mapeado [...] no puede ser el primer paso en el estudio del espacio reflejado en un texto literario, sino la consecuencia de un estudio previo que evalúe en qué medida el análisis textual puede enriquecerse a partir de las herramientas digitales (Martí, 2016).

Por ello, en nuestro trabajo no nos limitaremos a emplear TimeMapper como único método de análisis, sino como una herramienta auxiliar. A grandes rasgos, planteamos un análisis de la evolución del tratamiento del espacio físico en la poesía de Colinas, tanto cuantitativamente como cualitativamente, lo cual exploraremos y analizaremos empleando esta herramienta digital. Los resultados están disponibles en: http://timemapper.okfnlabs.org/shutteredmoon/antoniocolinas (consultado el 22 de diciembre de 2017).

En primer lugar, hemos dividido la obra coliniana en cuatro etapas. Aunque la clasificación de la literatura por movimientos, etapas, etc. siempre encierra algo de manipulación de la misma, es un criterio de gran utilidad para la organización de un estudio. Basaremos esta división en etapas de la obra poética de Antonio Colinas en otros estudios y en nuestros propios resultados. Hemos de tener en

\footnotetext{
${ }^{10}$ Disponible en http://www.educa.jccm.es/es/noticias/cervantes-libros-siglo-oro-linea-tiempo, consultado el 22 de diciembre de 2017.
} 
cuenta, además, que la obra de Colinas se presenta como muy ligada consigo misma ${ }^{11}$, lo que hace aún más difícil su organización. Atendiendo a la movilidad geográfica a lo largo de la vida del autor hemos dividido así su trayectoria: la primera etapa engloba su infancia y juventud en la península ibérica; la segunda, su estancia en Italia; la tercera, su experiencia en Ibiza y, finalmente, la cuarta, su regreso en la madurez a la península. Debido a la limitación de la extensión, hemos seleccionado una obra representativa de cada una de estas cuatro etapas y que será el foco de nuestro análisis. Así, este artículo presenta un análisis geoespacial de las obras: Poemas de la tierra y la sangre (1969), Sepulcro en Tarquinia (1976), Noche más allá de la noche (1982) y Libro de la Mansedumbre (1997), respectivamente.

A partir de esta selección, abordaremos la funcionalidad del espacio, cómo este es una parte fundamental para la cosmovisión del poeta, la frecuencia de las referencias geográficas y la alternancia del empleo de lugares evocados tanto específica como genéricamente. Paralelamente, iremos anotando las referencias espaciales en una hoja Excel que, posteriormente, podremos volcar en TimeMapper. Este etiquetado se limitará a referencias espaciales concretas y específicas como Bérgamo o León, pero obviaremos el etiquetado de zonas extensas como Inglaterra, Europa o Hispania porque entendemos que podría llevar a datos y conclusiones erróneas. Esto nos permitirá establecer un patrón visual para apoyar nuestro objetivo: cómo la experiencia vital de Colinas se proyecta en su poesía a través del espacio físico, de lugares tanto concretos como universales.

\section{Viajar por los poemas. Un recorrido a través de los espacios poéticos}

\section{1. Primera etapa: Poemas de la tierra y la sangre}

El primer periodo en la poesía de Colinas tiene a la península ibérica como el foco geográfico casi exclusivo de sus vivencias y de su poesía. Aunque el poeta disfruta desde joven de la movilidad geográfica y de su consecuente enriquecimiento personal, establece con su pueblo natal un fuerte vínculo. Su infancia en La Bañeza (León) le aporta una gran cercanía a la naturaleza y un aprecio hacia el paisaje leonés. Los montes, árboles, lagos y ríos conformarán un espacio que Martínez Fernández denomina como «originario» (2004: 14) y que, como veremos, estará siempre presente en la obra de Colinas. En 1961 el poeta se traslada a Córdoba, ciudad donde cursa tres años como bachiller y se acerca a la poesía. Posteriormente, en 1964, se va a Madrid para cursar sus Estudios de Ingeniería Técnica en la Escuela de Agrónomos de la Universidad Complutense. Cuatro años después se cierra esta época de juventud con la realización de un viaje por Londres y París, así como la superación del servicio militar en su tierra natal.

Esta etapa está marcada por variados lugares que aparecerán en diversas obras suyas como Córdoba adolescente (Colinas, 1997a), una colección de poemas escritos en 1963 durante su adolescencia en la ciudad de Córdoba y publicada mucho más tarde, o Truenos y flautas en un templo

\footnotetext{
${ }^{11}$ Dice al respecto J. L. García Martín: «Las referencias de unos libros a otros, de unos versos a otros, son constantes en Colinas, contribuyendo a la unidad obsesiva -pero nada monótona- de su mundo» (1996: 56).
} 
(Colinas, 1972), que comienza en París y se ve influido por la cultura francesa (Baudelaire, el Louvre...). Sin embargo, el paisaje leonés supone la principal fuente de inspiración para la localización de sus poemas. Un gran ejemplo lo encontramos con Preludios a una noche total (Colinas, 1969b), Accésit al Premio Adonáis en 1969, ya que esta obra supone una oda a la naturaleza que se recrea dentro de este 'espacio originario'. Esta obra supone un paso fundamental en la trayectoria del poeta, puesto que, como afirma el propio Colinas cuarenta y ocho años después, «Preludios fueron y son muy importantes para mí y para el conjunto de mi obra [...] porque en él ya se decanta la que era y habría de ser mi voz» (Colinas, 2015: 13).

En este poemario el tratamiento del espacio leonés es bastante difuso, se centra principalmente en un reflejo de la naturaleza, pero es una naturaleza que no posee un referente real concreto: «hacia la orilla del río y en los sotos» (v. 8, «Nocturno en río»), «la espina del zarzal» (v. 6, «Nocturno»). Quizás la influencia romántica o una aspiración universalista lleva al poeta a un tratamiento que evite la toponimia, una concreción espacial que convirtiese al poemario en un reflejo limitado de su experiencia vital y que oscureciese el tratamiento de los dos temas centrales del poemario. Debido a la ausencia de topónimos concretos en Preludios, hemos seleccionado, por el contrario, su primer poemario publicado: Poemas de la tierra y la sangre, donde la loa a las tierras leonesas favorece la localización geográfica de los poemas. Con este breve haz de poemas dedicados a la provincia de León, Colinas gana un premio con motivo de los dos mil años de la fundación romana de León, con cuya dotación puede viajar por París y Londres. Suponen, por tanto, su introducción y primer reconocimiento de la labor poética. En palabras del escritor, estos poemas:

Aun no ofrecían un lenguaje suficientemente depurado, pero revelaban muy bien mi entrañable pasión por lo telúrico, por aquellas tierras tan romanizadas del noroeste de las que yo me sentía en la ciudad continuamente desarraigado (Colinas, 1990: 29).

El poemario comienza con «Nocturno en León», un canto a esa ciudad, donde esta se describe como un espacio frío y asolado por el invierno que contrasta con la grandeza de su pasado, del que hoy solo quedan ruinas, «una muralla rota» (v. 7). Así, el poeta apostrofa a esa «Noble León, frontera de nieve más pura» (v. 18), la misma «Noble León, hoy nido sin susurros de pájaros» (v. 11). El segundo poema, «En San Isidoro beso la piedra de los siglos», también se sitúa en la ciudad de León, aunque se limita a uno de sus monumentos: la basílica de San Isidoro de León. En este poema la arquitectura cobra vida y se fusiona con los sentimientos de la voz lírica: «enclaustrada quietud» (v.3), «tumbas de eternidad» (v. 6), «dintel cansado» (v. 9), etc.

Por el contrario, el tono de «Mediodía de Sahagún de Campos» adquiere un tinte más ameno y positivo al crear una descripción que nos traslada al paisaje de Sahagún: «los llanos de eternidad» (v. 2), de «geografía amorosa» (v. 10) y de «brisa, pausada brisa» (v. 16). Lo mismo sucede con «Riberas del Órbigo», donde los sentimientos de la voz poética convergen con la naturaleza y le elevan; tal y como se recogen en estos dos versos: «Aquí en estas riberas que llevan hasta el llano / la nieve de las cumbres, planto sueños hermosos» (vv. 7-8). En la penúltima composición, «Barrios de luna», se acerca a su infancia a través de la mágica noche leonesa de esta localidad. En este poema expone su 
amor hacia las tierras leonesas, donde la noche y la magia ofrecen una atmósfera peculiar: «Crece mi amor hacia esta tierra / donde sentí la luna como una fiebre» (vv. 21-22). Finalmente, «Visión de invierno» alaba la impronta que la provincia leonesa ha dejado en el propio poeta, especialmente el León invernal, pues hasta «En la última llaga de tu ser, en la escarcha / de cada teja quiero dejar mi corazón» (vv. 16-17)

Así, en las seis composiciones de Poemas de la tierra y la sangre, se hace perceptible la importancia del espacio, puesto que todos ellos giran en torno al mismo. A grandes rasgos, el espacio leonés, invernal y nocturno junto con las sensaciones y evocaciones que despierta son los ejes conceptuales del poemario. Esta significación poemática se proyecta especialmente a través de dos recursos pragmáticos: el apóstrofe y el empleo de deícticos. Así, los poemas de apertura y de cierre suponen dos apóstrofes líricos, en los que el poeta personifica a la ciudad de León al transformarla en enunciataria: «Deja, León, que ponga muy dentro de tu entraña / de piedra oscura un beso» («Visión de Invierno», vv. 13-14).

Paralelamente, cabe destacar el empleo de deícticos espaciales de cercanía en el segundo, cuarto y quinto poemas. De hecho, la enunciación de estos tres poemas recurre siempre al demostrativo «este» y sus variantes y/o al adverbio «aquí». Cabe destacar que los poemas «En San Isidoro beso la piedra de los siglos» y «Riberas del Órbigo» enfatizan el empleo del deíctico «aquí» al colocarlo en posición anafórica de varios de sus versos, e, incluso, en «Riberas del Órbigo» se origina una estructura circular que enfatiza esta posición espacial, pues se abre y se cierra con los versos «Aquí en estas riberas donde atisbé la luz / por vez primera dejo también mi corazón» (vv. 1-2, 26-27). Asimismo, aunque se evoque el pasado infantil, el acto de enunciación se localiza siempre en ese punto geográfico. Se establece, por tanto, un continuo retorno:

Recuerdo que una vez siendo niño, esperé

la luna en estos valles de León. Era un pozo

De sueños cada instante. Y hoy vuelvo a este lugar (vv. 13-15).

Como podemos apreciar en la tabla (Tabla. 1), en todos los poemas se encuentran referencias a lugares geográficos concretos. En los cinco primeros poemas, las referencias se hacen patente ya desde sus títulos: León, San Isidoro de León, Sahagún de Campos, Órbigo y Barrios de luna, a los que debemos añadir el río Bernesga a su paso por la ciudad de León incluido en el último poema (v. 6). Curiosamente, contrasta de una forma totalmente antitética con el tratamiento de la geografía en Preludios a una noche total, escrito solo dos años después. Aunque ambos tienen como base el paisaje leonés (adivinable en ciertos pasajes), en Preludios se opta por la referencia al territorio leonés de forma genérica para favorecer la universalización del contenido; mientras que en Poemas la loa localista impone el empleo de topónimos concretos. Esta marcada presencia de la geografía posiblemente obedezca a la naturaleza del premio al que optó con el poemario, centrado en la provincia de León. 
Clara I. Martínez Cantón y Ana Rodríguez Pérez

Tabla 1

\begin{tabular}{|l|l|l|l|}
\hline & $\begin{array}{l}\text { N. }{ }^{\text {de }} \\
\text { poemas }\end{array}$ & $\begin{array}{l}\text { Poemas donde aparecen } \\
\text { espacios concretos }\end{array}$ & $\begin{array}{l}\text { Poemas donde aparecen } \\
\text { espacios genéricos }\end{array}$ \\
\hline $\begin{array}{l}\text { Poemas de la tierra y la } \\
\text { sangre }\end{array}$ & 6 & $6(100 \%)$ & - \\
\hline
\end{tabular}

Asimismo, si observamos la localización de estos espacios a través de TimeMapper (Fig. 1), consultable en http://timemapper.okfnlabs.org/shutteredmoon/antoniocolinas, encontramos que se limitan a cuatro puntos: la capital León, Sahagún, el Órbigo y Barrios de luna. León se coloca en el centro del mapa y el resto de los espacios giran en torno a esta ciudad, tanto en el mapa como el poema. De hecho, los poemas de apertura y de cierre se centran en la ciudad. Asimismo, podemos comprobar cómo en esta primera etapa la cosmovisión del poeta se aferra a unas pocas y cercanas coordenadas espaciales, donde consigue encontrar su vía de escape en la naturaleza fuera de «la sociedad española de aquellos días» que apenas «parecía ofrecer excesivos estímulos» (Colinas, 1990: 31). De hecho, a la vez que se amplifica su experiencia vital, va creciendo la amplitud del mapa:

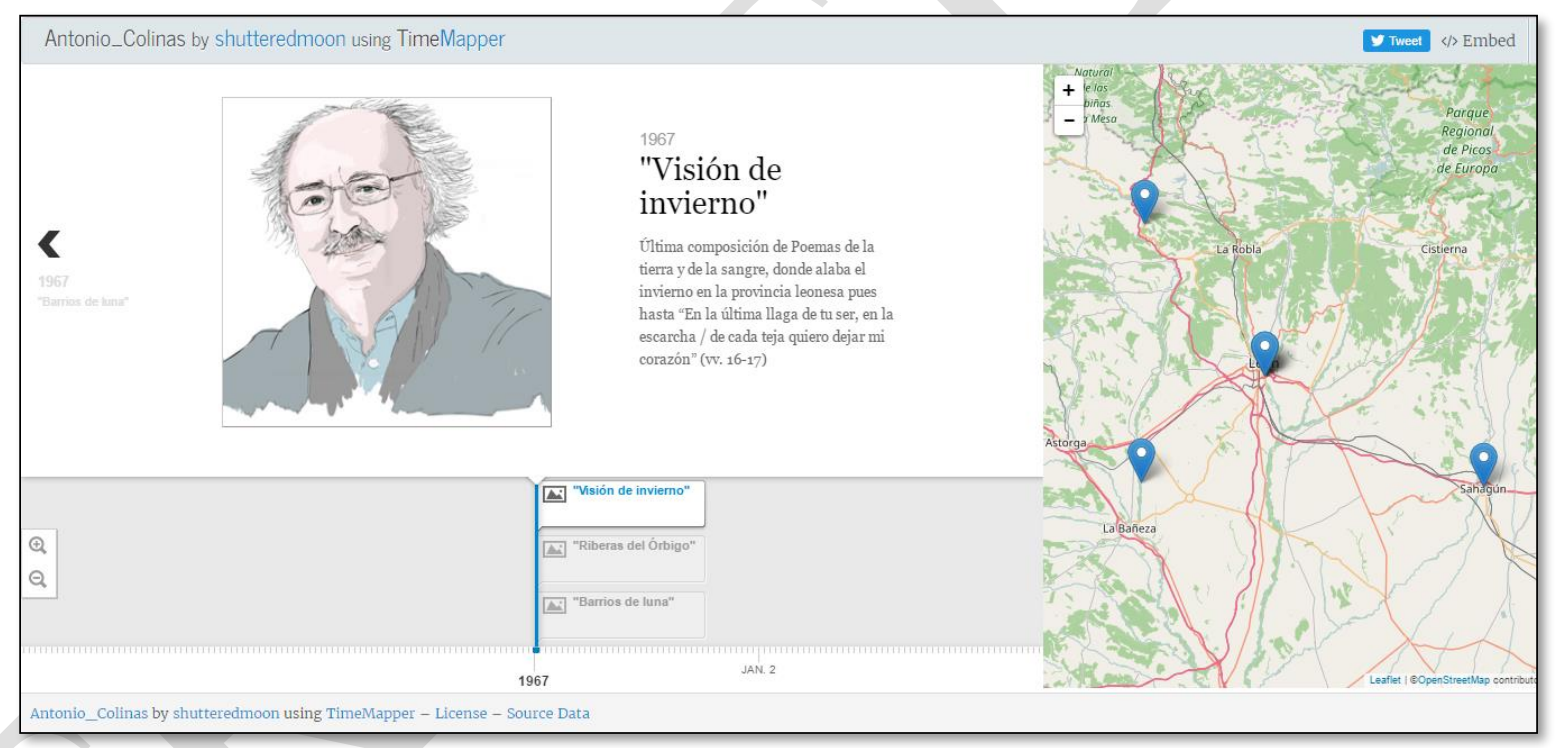

Fig. 1. Visualización con TimeMapper de las coordenadas geográficas en las que se inscribe el poemario Poemas de la tierra y la sangre

\section{2. Segunda etapa: Sepulcro en Tarquinia}

La estancia de Colinas en Italia como lector de español en las universidades de Milán y Bérgamo (1971 - 1974) marca también su poesía, especialmente por la impronta más cercana al culturalismo. El propio Colinas afirma que, tras su servicio militar, después «del frío y negro sueño de aquel invierno en León había de brotar un sueño dorado y pleno: el de la luz e Italia» (1990: 31). Este país supone un punto de inflexión en la poesía coliniana puesto que contrarresta la realidad cotidiana de la cerrazón sociopolítica de la España de la época. Como expone Martínez García: 


\section{Tropelías. Revista de Teoría de la Literatura y Literatura Comparada, 30 (2018)}

Un viaje a través de los poemas: acercamiento al tratamiento espacial en la poesía de A. Colinas

Italia: el deslumbramiento [...], un mundo nuevo, abierto e inconmensurable, contrapuesto catárticamente al mundo enclaustrado que conocía, el helenismo saturado de esencias inagotables, la latinidad [..], el renacimiento ambiental [...] (1990: 42).

Como obra representativa de esta etapa hemos seleccionado Sepulcro en Tarquinia (1975), que recibió el Premio de la Crítica en 1976. Este es, quizás, uno de sus poemas más conocidos, donde se funde la memoria, la historia, la arqueología y la experiencia. Tildado de culturalista, la alta frecuencia de referencias externas no permite oscurecer su significación, sino que la apoya y la refuerza con gran viveza. En relación con el espacio, quizás sí exista un deseo de manifestar la necesidad de la concreción espacial a través de múltiples referencias; pero también debe valorarse la cercanía temporal de la experiencia.

Concretamente, el poemario se estructura en cuatro partes: las dos primeras partes del poemario giran en torno a Italia y las dos segundas suponen un retorno a sus orígenes en el noroeste español. En palabras del propio autor, esta división responde a «una lucha feroz entre dos mundos, entre dos concepciones de la realidad, entre dos paisajes» (1990: 33), y prosigue:

Las dos primeras partes del libro luchan con la tercera y la cuarta. En las primeras está el mundo latino. En las segundas, esa realidad que, como tan bien ha señalado Francisco Brines, yo redescubro subterráneamente, por debajo del tiempo y de la Historia, mis tierras del Noroeste (1990: 33).

Sin embargo, aunque exista una oposición en el ámbito espacial entre las partes primera y segunda y las partes tercera y cuarta, no hay una contraposición real, ya que en el fondo el ámbito temático se funde: de nuevo la piedra, como símbolo de lo duradero, frente a la brevedad de la existencia humana; y reaparece con gran intensidad la naturaleza, el cosmos -poemas como «Novalis» o «Poseidonia, vencedora del tiempo»-. Son, como afirma Martínez Fernández «espacios complementarios» (2004: 73).

Los primeros diez poemas nos llevan de su mano por las sensaciones que despiertan en él Venecia, Bérgamo, Florencia, Milán, etc., mientras que la segunda parte la ocupa el poema «Sepulcro en Tarquinia» y que da nombre al poemario. Frente a la primera etapa del autor, donde la evocación del espacio de la infancia se hace desde una distancia temporal, las dos primeras partes de Sepulcro en Tarquinia son más cercanas a las vivencias del poeta: escribe a la vez que disfruta de la experiencia italiana. Esto parece concretarse lingüística y referencialmente a través de espacios muy definidos, incluso todos los títulos de esta primera parte -exceptuando «Simonetta Vespucci», y «Novalis» recogen núcleos urbanos específicos a los que se loa. Los topónimos inundan la composición e incluso se convierten en el motivo central de propio poema: «Piedras de Bérgamo» o «Lago de Trasimeno».

Asimismo, este espacio se sitúa cronológicamente en dos coordenadas temporales diferentes: el pasado y el presente. Junto a las ruinas, columnas y bellos paisajes naturales, el pasado renacentista revive. En el primer poema, por ejemplo, se establece una loa a la belleza de Simonetta Vespucci, que fue retratada por diversos pintores renacentistas asentados en Florencia y, por ello, aparece tanto «de virgen o de amante / Ya Judith despeinada / o Venus húmeda» (vv.7-9). Otro ejemplo lo encontramos en «Giacomo Casanova acepta el cargo de bibliotecario que le ofrece en Bohemia el conde de 
Waldstein», donde el poeta cede la voz a Giacomo Casanova que, acogido por el conde de Walstein, ofrece una reflexión sobre sus avatares y cómo estos le llevaron a recorrer el mundo. Así, afirma que «Fui abad entre los muros de Roma y era hermoso /ser soldado en las noches ardientes de Corfú» (v. 7-8), «Escuchadme, Señor: de Madrid a Moscú / he viajado en vano,» (v.11-12) y todavía «sueño con los serrallos azules de Estambul» (v.19).

Por el contrario, en otros poemas, el espacio no evoca otras épocas, sino que está totalmente actualizado. En «Piedras de Bérgamo» el poeta nos ofrece un recorrido por la ciudad a la vez que nos describe los sentimientos que le despierta. Para ello, va mencionando diferentes espacios directamente a modo de estampas de la ciudad como «San Vigilio» o la «cappella Coleoni» (v. 35), y seguidamente expone su percepción: «Y aquí, en Borgo Canale, / todo es manso y sublime» (vv. 36-37). Otras veces, simplemente hace referencias más vagas como «Espiaba la plaza más hermosa del mundo / detrás de las cortinas del palacio barroco» (vv.39-40).

En esta parte también se recogen dos poemas que nos trasladan a otros espacios europeos: «Vamos, vamos a Europa» y «Noviembre en Inglaterra». No debemos olvidar que Colinas ya había visitado Londres y París que, junto con la experiencia italiana, parece conformar en su poesía un deseo de conformar un espíritu transfronterizo y universalizador de la geografía. La experiencia espacial parece conformarse en la creación de un mundo poético sin fronteras, por el que se viaja y se experimenta. La segunda parte, conformada únicamente por «Sepulcro en Tarquinia», supone un largo poema donde se secuencian diferentes imágenes y espacios que recrean un collage de lo italiano: Bérgamo, Sirmio, Tarquinia, el lago Trasimeno, Murano...

Asimismo, la tercera y cuarta partes están centradas, de nuevo, en las raíces peninsulares, donde la toponimia se reduce a muy pocos lugares concretos: Trasmontes, Castra Petavonium, la Piñotrera y Peña Trevinca. Parece en muchos casos que se busca retomar el tratamiento universalizador del espacio peninsular que ya aparecía en Preludios: el bosque de carvalhos (v. 9, «No se aleja en los mesones sino bajo el cielo estrellado»), el campamento («A la salida del campamento la calzada cruza un desfiladero»), etc. Esta segunda parte se compone de otras dos partes: «Castra Petavonium», conformado por ocho poemas, y «Dos poemas con luz negra» - los cuales no trataremos puesto que no recogen ningún espacio. Como bien sintetiza Agustín Fernández:

En la tercera parte, «Castra Petavonium», se aprecian algunos cambios: hay una vuelta a los orígenes, al noroeste leonés de las primeras composiciones, aunque con un tono bien distinto. La inflexión resulta sorprendente, hay un gusto por lo feo, por lo escatológico. Se produce un cambio en la estética (Agustín Fernández, 2011: 123).

A grandes rasgos, este tratamiento espacial se proyecta a lo largo del poemario con los mismos recursos que ya recogiéramos en Poemas, dos recursos pragmáticos: el apóstrofe y el empleo de deícticos. En relación con el empleo de los deícticos espaciales, sigue siendo frecuente la aparición del demostrativo de cercanía «este» y sus variantes, aunque ahora se intercala con el de lejanía «aquel» y sus variantes. Por ello, encontramos varios ejemplos del demostrativo «este» para referenciar espacios contextuales como «desde este monte» («Poseidonia», v.5) o «lejos de este bosque de castaños» («Trasmontes», 1. 6) que acercan y actualizan la posición del autor, pero también se registra el empleo 
de los demostrativos de lejanía «aquel» y sus variantes para resaltar la evocación del pasado: «el agua de aquel mármol vetada» («Sepulcro en Tarquinia», v. 48). Sucede lo mismo con el adverbio «aquí», puesto que se recoge una menor incidencia y se intercala con las formas de lejanía «allá» y «allí» para conseguir un fuerte efecto evocador como «allí, junto al canal de aguas muy verdes» (v. 2) o «allá en Inglaterra» (v. 1).

Paralelamente, la incidencia de los apóstrofes líricos a las ciudades, así como su importancia también es menor. Pero no por ello pierden su belleza y su fuerza expresiva como se refleja en el apóstrofe a la ciudad de Bérgamo en «Piedras de Bérgamo»:

Déjame que me abrumen tus conventos inmensos, quiero ver degollados los leones de mármol, quiero volver los ojos y encontrarte imponente, toda tu catedral alzada sobre el valle (vv. 22-25).

Tabla 2

\begin{tabular}{|l|l|l|l|}
\hline & $\begin{array}{l}\text { N. } \\
\text { poemas de }\end{array}$ & $\begin{array}{l}\text { Poemas donde aparecen } \\
\text { espacios concretos }\end{array}$ & $\begin{array}{l}\text { Poemas donde aparecen } \\
\text { espacios genéricos }\end{array}$ \\
\hline «Piedras de Bérgamo» & 10 & $9(90 \%)$ & - \\
\hline «Sepulcro en Tarquinia» & 1 & $1(100 \%)$ & - \\
\hline «Castra Petavonium», & 8 & $4(50 \%)$ & $2(25 \%)$ \\
\hline «Dos poemas con luz negra & 2 & - & $1(50 \%)$ \\
\hline Total & 21 & $14(66,6 \%)$ & $7(14,2 \%)$ \\
\hline
\end{tabular}

Finalmente, como podemos apreciar en el cuadro (Tabla 2), tampoco encontramos en todos los poemas referencias a lugares geográficos concretos. Frente al $100 \%$ de la localización geográfica en Poemas de la tierra y la sangre, Sepulcro solo recoge un 66,6\% de referencias geográficas concretas. Asimismo, se recogen tres poemas, el 14,2\%, donde esta localización debe inferirse: «A la salida del campamento la calzada cruza un desfiladero», «A un brazo de bronce» $\mathrm{y}$ «Mysterium fascinans». En el caso de «A la salida del campamento la calzada cruza un desfiladero» $\mathrm{y}$ «A un brazo de bronce» parece claro que el emplazamiento es el yacimiento de Petavonium, en el valle de Vidriales, Zamora, cerca del pueblo donde el autor pasaba sus veranos de infancia, y sobre el que ha escrito en más ocasiones. En el caso de «Mysterium fascinans», la referencia a rosetón, vidrieras y la propiamente nombrada catedral hace pensar en la pulchra leonina, la catedral de la ciudad de León. En el poema de «Novalis», no existen referentes geográficos, sino que se habla a la noche como concepto genérico.

Además, si observamos la localización de estos espacios a través de TimeMapper (Fig. 2), encontramos que frente a la limitación geográfica leonesa de Poemas de la tierra y la sangre, Sepulcro en Tarquinia ofrece una mayor expansión territorial que tiene como foco principal la cultura europea (Italia, Bohemia, Inglaterra, Europa). Con ello, podemos comprobar como en esta segunda etapa la 
cosmovisión del poeta se expande a través de las coordenadas espaciales. Como ya hemos mencionado, la experiencia vital del poeta supone una expansión espacial de su poesía.

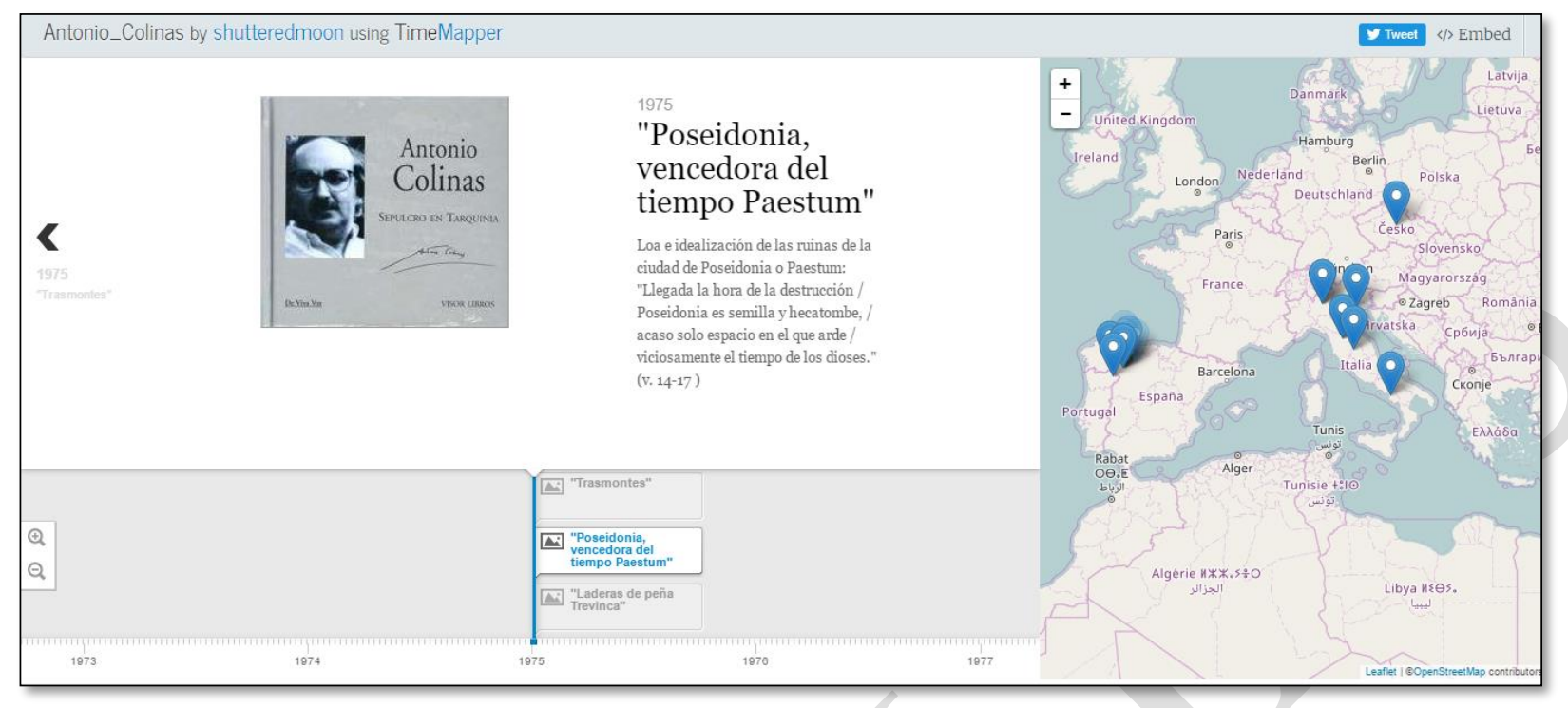

Fig. 2. Visualización con TimeMapper de las coordenadas geográficas en las que se inscribe el poemario Sepulcro en Tarquinia

\section{3. Tercera etapa: Noche más allá de la noche}

Tras su estancia en Italia, Antonio Colinas regresa a España y se asienta en Madrid. Durante tres años, su labor con la pluma se enfoca hacia la traducción, la prensa..., pero su producción poética parece resentirse debido a la naturaleza «dura y vacía de la urbe» (Colinas, 1990: 34). Este vacío le lleva a replantearse un nuevo traslado de residencia, la búsqueda de un nuevo espacio que le permitiese volver a encontrar a su yo poético. Se perfiló, por tanto, en su mente la idea de mudarse a Ibiza, como en su momento había hecho con Italia: «Se repetían los hechos. Otra vez, cíclicamente, había que negar el mundo para poseerlo en cuanto éste tiene de más esencial» (Colinas, 1990: 35). Así, se abre una nueva puerta a una época fecunda: Astrolabio (1979), Noche más allá de la noche (1983), Jardín de Orfeo (1988) y Nuevo tratado de armonía (1999), una poética que incorporará el simbolismo del mar y donde la luz adquirirá mayor importancia. Afirma el propio poeta:

En mi poesía hay varias etapas: en algunas estará más presente la cultura. Hay un componente también en otras de lo que el profesor Paulino Ayuso ha reconocido como irracionalismo. Hay, sobre todo, a partir de Astrolabio, una poesía más reflexiva; y hay al final, sobre todo partiendo de Los silencios del fuego, lo que yo reconozco como «poética de la mansedumbre», que es la apuesta por un humanismo abierto y concreto. Así que emoción, intensidad, pureza formal en este primer poema [se refiere a «Nacimiento al amor» de Preludios] como características que van a estar latentes en mi poesía (Colinas, 2002: 138).

Como obra clave para representar esta etapa hemos seleccionado Noche más allá de la noche (Colinas, 1982). Esta selección responde a su importancia, ampliamente reconocida: «poemario muy significativo dentro del conjunto de la obra del escritor leonés» (Martínez Cantón, 2011: 134), «un libro cumbre en la trayectoria poética de Antonio Colinas» (Vilas Vidal, 1990: 61), «la más alta cima de su producción poética» (Martínez Fernández, 2004: 92). Concretamente, esta obra se conforma con 
treinta y cinco cantos sin título y un post-scriptum donde el poeta vuelca su experiencia vital (el dolor ante la muerte de un amigo, el mar, el nacimiento de su hijo...), así como la plasmación de una exploración metafísica sobre el propio conocimiento interior. Esta búsqueda del ser parece derivar de las lecturas que realiza en la isla. De este modo, se verá influenciado por diversos pensamientos orientales como el pitagorismo, el orfismo, el taoísmo o el confucianismo, así como por las lecturas de María Zambrano o Mircea Eliade.

En relación con el tratamiento espacial, la obra mantiene esa impronta coliniana de la relación entre poesía y geografía aunque, como veremos, se va alejando de la concreción de las coordenadas espaciales hacia una mayor ambigüedad en la localización. De hecho, incluso evoca espacios geográficos de mayor amplitud: Hispania, Mediterráneo y Al-Ándalus, como símbolos de una unidad cultural universal. Como ya había hecho en Sepulcro en Tarquinia, Colinas mantiene el espacio originario leonés, a la vez que incorpora la nueva realidad que está viviendo: Ibiza. Sin embargo, tras su experiencia italiana, Colinas tampoco parece querer abandonar esta cultura; por lo que se fusionará con la experiencia ibicenca a través de una exaltación de una cultura mediterránea como un único ente donde se aúnan Italia e Ibiza (el mar, los acantilados, el monte Vesubio, Cumas...). Así, esta experiencia se reflejará de una forma distinta a la italiana. Frente a la admiración más urbanita y culturalista que le aporta la Italia renacentista y del Imperio romano, Ibiza le ofrecerá una armónica naturaleza y, sobre todo, el descubrimiento del mar.

Como ya recogíamos en Poemas y en Sepulcro, este tratamiento espacial se proyecta en el texto con los mismos recursos pragmáticos: el apóstrofe y el empleo de deícticos, aunque en esta obra aparece una nueva figura: el circunloquio. En relación con el empleo de los deícticos espaciales, sigue siendo frecuente la aparición de los demostrativos «este» y «aquel», junto con sus variantes, así como los adverbios «aquí» y «allá». En este sentido, llaman la atención los cantos XXIX, XXX y XXI, localizados en el monte Teleno y en el Guiana (monte Aquiana), puesto que existe una relación metafórica espacial muy fuerte entre la subida a estos montes, la rememoración de la infancia y el alcance de la cima del conocimiento:

\footnotetext{
Al final de las tierras, más allá de los límites, entre verdosos tesos de heladoras herrumbres, tras los místicos valles de enfermiza pureza, aun vemos entreabrirse el misterio de un monte (vv. 1-4).
}

Sin embargo, solo se registran dos apóstrofes espaciales: al Partenón y a la ciudad de Venecia. El canto IX es un precioso poema que alaba al templo griego como un símbolo del deseo del hombre de conocer y desvelar el misterio de la existencia, pero también de la trascendencia del conocimiento emanado por la cultura griega. Así, «De ti brota armonía, que genera la música. / En ti nacen los números, que desvelan los símbolos» (vv. 12-13). El otro apóstrofe lo encontramos en el canto XIV, en una alabanza a la belleza de la ciudad de Venecia gracias al influjo de la cultura renacentista. Esta ciudad se equipara a la diosa Venus y se la describe como la «perfección de los siglos en tu figura pura» (v.9) 
El último recurso registrado en este poemario es el empleo de circunloquios para evocar el espacio y que supone una novedad en la poética coliniana para el tratamiento del espacio. En el canto III, por ejemplo, se refiere a las islas de Ibiza y Formentera a través de la perífrasis «las dos verdes islas de Diana enamorada» (v. 10), que hace referencia al libro primero de la Diana enamorada (1564) de Gil Polo, como señala Martínez Fernández (Martínez Fernández, 2004: 196). En el canto VI encontramos otro ejemplo, donde el poeta elide la referencia directa a la cueva de Es Cuieram, en la cala de San Vicente (Ibiza) a favor de la perífrasis «la caverna perdida de la diosa» (v.2), como indica de nuevo Martínez Fernández (Martínez Fernández, 2004: 199).

Seguidamente, como podemos apreciar en el cuadro (Tabla. 3), podemos observar un descenso paulatino de las referencias a lugares geográficos concretos dentro de su obra poética. Frente al 100\% de la localización geográfica en Poemas de la tierra y la sangre, en Sepulcro en Tarquinia ya se aprecia una considerable disminución a un 66,6\% de referencias geográficas concretas. En Noche más allá de la noche el porcentaje se reduce levemente a un 50\%. Asimismo, se recogen seis poemas, el 16,67\% del total del poemario, donde esta localización aparece referenciada de forma genérica. En los cantos IV, V, XXVI y XXVII se observa la referencia a espacios naturales, plausiblemente ibicencos, donde se aprecia el contraste del mar frente al bosque y al cielo, como lugares armónicos: «Allá entre los cipreses, sobre el lomo del mar, / veíamos saltar los felices delfines» (IV: vv. 1-2), o como espacios divinizados o misteriosos: «A lo largo del día subimos monte arriba / sin hallar la caverna secreta que buscábamos» (V: vv. 1-2). Por el contrario, los poemas XII y XIII nos llevan a dos espacios difusos, «con fuerte contraste entre sí» (Martínez Fernández, 2004: 102), para representar la ambigüedad del mundo medieval. Mientras que el canto XII presenta un locus eremus, el XIII nos lleva a la luz irradiada gracias al amor idealizado. Así, se sucede una fuerte oposición entre los «Pellejos de la peste, pestilentes pajares, [...] palomares sin techo, secos pozos, cadáveres» (XII: vv. 1-3) a la primavera (XIII: v.2) que anuncia al amor y la llegada del Renacimiento, permitiendo que «los dos vagaron luego, / durante mucho tiempo, por un hermoso valle» (XIII: vv. 17-18).

Tabla 3

\begin{tabular}{|l|c|c|c|}
\hline & $\begin{array}{c}\text { N. }{ }^{\text {o de }} \\
\text { poemas }\end{array}$ & $\begin{array}{c}\text { Poemas donde aparecen } \\
\text { espacios concretos }\end{array}$ & $\begin{array}{c}\text { Poemas donde aparecen } \\
\text { espacios genéricos }\end{array}$ \\
\hline $\begin{array}{l}\text { Noche más allá de la } \\
\text { noche }\end{array}$ & 36 & $18(50 \%)$ & $6(16,67 \%)$ \\
\hline
\end{tabular}

La concreción geográfica es más abundante al principio del poemario, mientras que hacia el final hay una mayor ambigüedad espacial. Esta concreción se proyecta, como ya sucedía en Sepulcro en Tarquinia, hacia dos espacios en coordenadas temporales diferentes: el presente y el pasado. Así, algunos poemas se enuncian en el tiempo ad oculus como en «aquí, en esta ladera que cubre el olivar» 
(I: v. 3) o «Pero hoy la primavera aun pasa incendiando, / las islas y en el mar crece el fuego con fuerza» (III: vv. 21-22)

Por el contrario, otros poemas nos trasladan hacia el mundo grecolatino (cantos VIII, IX, X, XI), a la época medieval (cantos XII y XIII) y al Renacimiento de los místicos (XV, XVI, XVII). El canto VIII, por ejemplo, evoca los viajes de Ulises como una analogía de la búsqueda del conocimiento. El griego navega hasta límites insospechables, incluso «tras las columnas de Hércules» (v. 11) hasta llevarle a la nada - a «un mar sin gentes, soledad infinita» (v. 12) - gobernada por un todo, «una presencia inhumana» (v. 22). Este pasado también puede ser el del propio poeta, donde expone sus recuerdos infantiles sobre el paisaje leonés: «los recordé de nuevo el pasado verano /en aquel monte oscuro que sostenía estrellas» (XXXI: vv. 3-4)- o donde recrea experiencias místicas:

\footnotetext{
Una tarde, en Toledo, cuando yo era muy joven perdí el conocimiento a la orilla del río de Garcilaso, cerca de aquellos altos muros por donde descendió, por escala de música, Juan de Yepes, herido de divina poesía (v. 1-5).
}

Finalmente, si geolocalizamos estos espacios a través de TimeMapper (Fig. 3), encontramos que frente a la limitación geográfica leonesa de Poemas de la tierra y la sangre o la expansión europeísta de Sepulcro en Tarquinia, Noche más allá de la noche se esparce a través del Mediterráneo. Con ello, «va más allá de las fronteras del noroeste natal e incluso de todo el macroespacio ibérico, la visión poética se hace cosmovisión y traduce una vez más el sentimiento de totalidad propio de esta lírica» (Tadoun, 2009: 268). Asimismo, también comprobamos que las tierras leonesas todavía mantienen una fuerte presencia en la construcción de la poética coliniana. Esto implica que la cosmovisión del poeta de la tercera etapa busca una universalización de su poesía a través de la unión marítima y cultural del mundo grecolatino con el de sus orígenes: mar e interior montañoso (especialmente el monte Teleno, cumbre que preside el horizonte de su tierra natal, La Bañeza). Volvemos a evidenciar

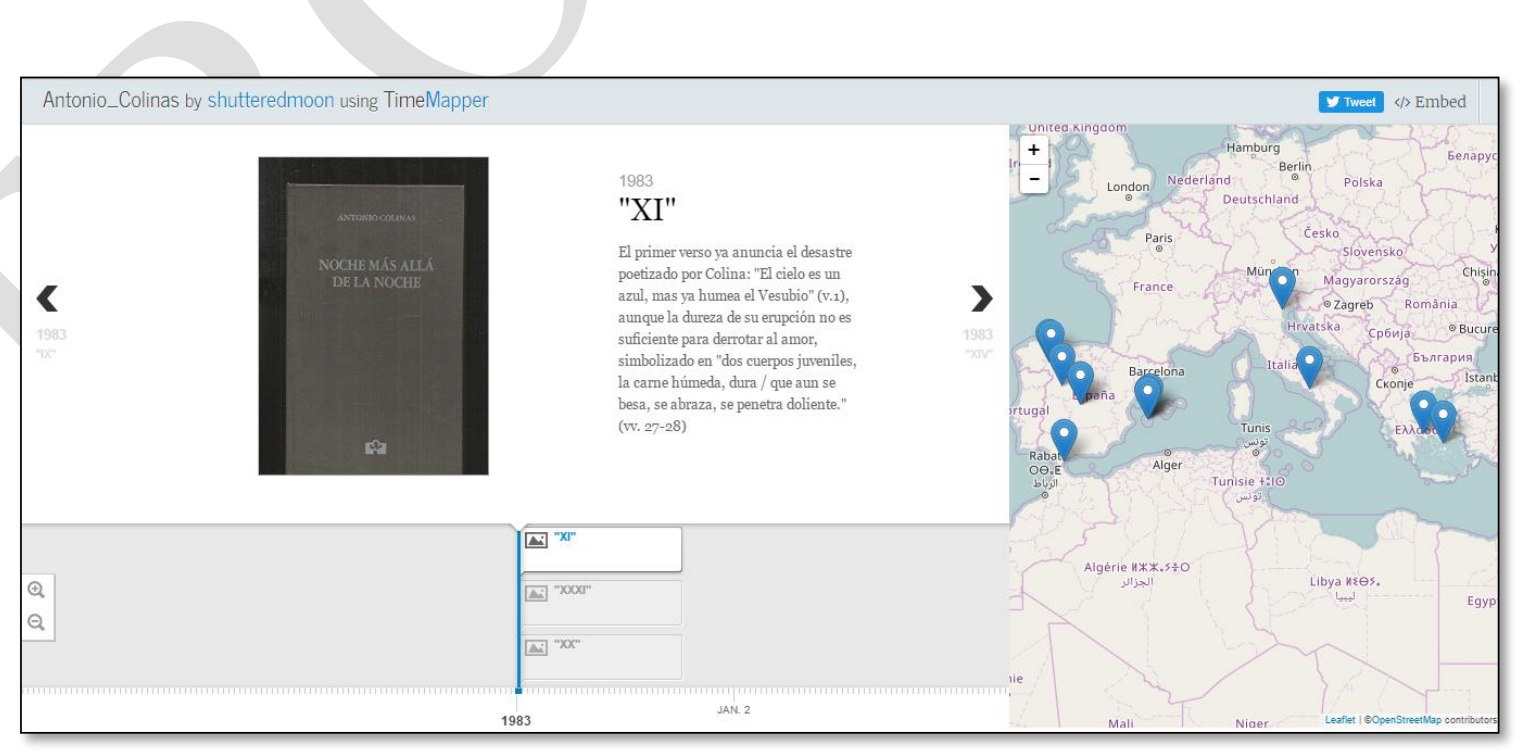

Fig. 3. Visualización con TimeMapper de las coordenadas geográficas en las que se inscribe el poemario Noche más allá de la noche 
que la geografía vital del poeta no es una nimia anécdota, sino que embarga su pensamiento y, por tanto, su poética.

\section{4. Cuarta etapa: Libro de la mansedumbre}

Finalmente, dentro de la última etapa coliniana, cabe destacar su regreso al noroeste peninsular en 1998. Los últimos años en la isla junto con su traslado a Salamanca conforman otro nuevo ciclo productivo dentro de su poética: la etapa de la mansedumbre. Esta ha sido «caracterizada [...] por preocupaciones éticas y ecológicas y una mayor clarificación del lenguaje» (Martínez Fernández, 2004: 247), en la que «se ha destacado esa denuncia de un mundo cada vez menos armonioso y respetuoso (destrucción de la naturaleza, guerras, etc.)» (Martínez Cantón, 2011: 78). Este periodo se configura con una trilogía poética configurada por el Libro de la mansedumbre, que da nombre a esta etapa, junto con Los silencios del fuego (1992) y Tiempo y abismo (2002), si bien se suele completar con el libro posterior Desiertos de la luz (2008).

Para el presente análisis hemos seleccionado el Libro de la mansedumbre (Colinas, 1997b), puesto que parece representar el mundo interior de esta etapa plena, de madurez ideológica, así como un puente entre la isla y el noroeste. Concretamente, este poemario muestra una estructura tripartita formada por «Aunque es de noche», «Manantial de luz»y «La tumba negra». La primera parte recibe el nombre del tercer poema, el cual hace referencia a un verso de la composición «Cantar del alma que se huelga de conocer a Dios por su fe» de San Juan de la Cruz. Estos nueve poemas se caracterizan por una tendencia a reflejar la plenitud que embarga al poeta, fundamentalmente a través de la fuerte presencia del amor y de la luz, pero también de la muerte y del mal.

Espacialmente, esto se proyecta en la evocación de espacios genéricos: el mar, el bosque, el valle y el jardín, que parten de la propia experiencia conocida del poeta en Italia, Ibiza y León. Al limitarse al empleo de sustantivos genéricos, y no a la concreción geográfica, consigue que esta primera etapa alcance un halo de mayor universalización frente al resto del poemario, pero también una mayor interiorización en el mundo desde una concepción social. De hecho, solo se recoge una única referencia concreta en el poema «La llama» y que se limita a ser un símbolo de la interioridad del poeta, «el sueño de los lugares armónicos - Grecia» (Martínez Fernández, 2004: 114): «por el agua de un monte / que suena entre cipreses en un lugar de Grecia» (vv.12-13).

Ya no se trata de reflejar las impresiones de las ruinas, el arte o la belleza natural, ni de expresar la importancia de alcanzar la cima del conocimiento o querer desentrañar los misterios del ser; sino que es una etapa donde se desplaza la impronta más filosófica de Colinas hacia una percepción de los problemas más terrenales. Así, frente a espacios idílicos y armónicos que reflejan este cénit personal en donde el sujeto lírico se sitúa cerca «de suaves jardines, / a la orilla de un mar calmo y antiguo» («La llama»: vv. 27-28), se registran espacios que adquieren connotaciones telúricas e, incluso, desgarradoras, como en «El olivo azul», donde se relata el descubrimiento del cuerpo de una joven muerta. En «La visita del mal», por ejemplo, nos advierte que «le hemos abierto / de par en par la puerta de casa» (vv. 5-6) al mal, aunque nuestro poeta lo logra vencer ofreciéndole con «calma» (v. 10) y «sosegada paz» (v. 29). Mientras que en las etapas anteriores se loaban bosques o se poetizaba 
el mar y se ascendían montes, ahora la situación de los espacios naturales se convierte en motivo de denuncia:

No cesan de avanzar

Por el bosque las hachas y las sierras

De quienes urbanizan («El valle, frontera de los siglos», vv. 4-6).

Por el contrario, la segunda parte del poemario, que consta de quince poemas, presenta una mayor presencia de las coordenadas geográficas concretas, puesto que se recogen en siete poemas (fig. 7). En esta parte, el tratamiento del espacio mantiene ese doble simbolismo de lo universal y lo particular que ya se reflejaba en la segunda y tercera etapa coliniana como muestran los títulos de «Sintra» y «La ladera de los podencos». Volvemos, por ello, a encontrar referencias a ciudades y a templos (como en los tres poemarios analizados anteriormente), que se convierten en motivo de alabanza o de analogía de una idea. Un claro ejemplo es el poema «Sintra», donde Colinas contrasta el soberbio pasado de la ciudad portuguesa «con sus colores de antiguo esplendor» (v. 24) frente a la actualidad, donde la ciudad se ha convertido «en una umbría con ruinas» (v. 14). Mientras que «En la luz (El Parral)», el ascenso al Monasterio del Parral se convierte en una analogía de la búsqueda de la luz, del conocimiento: «esa pura luz que nos acoge (en el silencio del monte piadoso)» (vv. 12-13). No es casual la elección de este espacio, pues en el yace San Juan de la Cruz, poeta místico admirado por Colinas.

Cabe destacar que, por primera vez, Colinas abandona la referencia geográfica limitada al continente europeo. El segundo poema de esta etapa, «Coayacán», busca exponer la convergencia de los contrarios, del amor y de la sangre a través de una sugestiva recreación que nos traslada a México. Allí, recorremos «una calle empedrada, / colonial y desierta» (vv. 3-4) de Coyoacán hasta encontrarnos con una mujer «misteriosa y sin rostro» (v.13). Esta mujer es lo único que destaca «en medio del osario de la Historia» (v. 20), simbolizando cómo el amor se eleva sobre toda la sangre derramada en el pasado.

Finalmente, la tercera parte de este poemario está compuesta únicamente por el largo poema «La tumba negra» con motivo de su viaje por Alemania. A través de su lectura podemos acompañar a Colinas, subirnos en el tren y empaparnos de las impresiones que le despiertan estos escenarios: la naturaleza, el arte, la música, la literatura, la filosofía y la reciente historia de los totalitarismos reflejados en la arquitectura. La fuerte presencia de los topónimos - Leipzig, Turingia, Halle, Köthen, Jena, Weimar y Brandenburg - nos recuerda a la composición de Sepulcro en Tarquinia, así como múltiples referencias espaciales tan concretas a calles, museos o parques consigue crear un magistral juego poético que simula la travesía. El siguiente fragmento, por ejemplo, es una muestra de esta experiencia que nos traslada a suelo alemán:

Más tarde, cuando íbamos dejando las penumbras de Weimar en su dulce olvido - poco antes de la Escuela de Música Franz Liszt, cerca del busto de Pushkin y de la callecita de Bettina Brentano (vv. 192-196). 
Frente al resto de los poemarios analizados, El libro de la mansedumbre ya no presenta el mismo uso de figuras para designar el espacio. Ya no se reflejan los apóstrofes líricos presentes en los tres poemarios anteriores o el empleo de circunloquios en Noche más allá de la noche. Por el contrario, sí que se mantiene el empleo de los deícticos espaciales - los demostrativos «este»y «aquel», junto con sus variantes, así como los adverbios de lugar «aquí» y «allá». A modo de ejemplo, «La dama blanca (Monasterio de la Veracruz)» es un poema que evoca la fascinación y misterio que emana del monasterio de la Veracruz en Salamanca. Gracias a la presencia del deíctico «aquí», la voz poética nos traslada al templo y lo convierte en parte del contexto espacial de la enunciación: «Pero aquí dentro (nada de la nada) / se afervora un hondísimo misterio» (v. 5-6). Tampoco encontramos poemas cuyas coordenadas espaciales se localicen en el pasado como es frecuente en Noche más allá de la noche (el mundo grecolatino, el medieval...) y en Sepulcro en Tarquinia (la Italia renacentista y la Iberia romana), sino que se refleja la preocupación coliniana por la actualidad que le rodea.

Además, como hemos ido apreciando a lo largo del presente trabajo, el análisis de la recurrencia a la concreción geográfica nos indica que se consolida el paulatino descenso. De la total presencia toponímica en Poemas de la tierra y la sangre, el 66,6 \% en Sepulcro en Tarquinia y el 50\% en Noche más allá de la noche, nos encontramos ahora que la concreción se limita al 36\%. Este descenso no parece indicar una disolución entre la poética coliniana y la impronta espacial, sino que se resuelve en un aumento de la localización del poema dentro de espacios más genéricos llegando a conformar el 52 $\%$ de los poemas (fig.7). Así, en «Descenso a la mansedumbre» se evoca al mar y a la playa, lugares universales que no son localizables en un mapa. Aunque el lector pueda llegar a inferir que se trata de una referencia a Ibiza si conoce la trayectoria del poeta, su primera lectura activará en su mente un espacio genérico y de simbología universal.

¡Cómo revela el mar la mansedumbre! Aquí en la playa, donde están los límites Verdaderos del ser (vv. 1-3).

Tabla 4

\begin{tabular}{|l|c|c|c|}
\hline & $\begin{array}{c}\text { N. }{ }^{\circ} \text { de } \\
\text { poemas }\end{array}$ & $\begin{array}{c}\text { Poemas donde aparecen } \\
\text { espacios concretos }\end{array}$ & $\begin{array}{c}\text { Poemas donde aparecen espacios } \\
\text { genéricos }\end{array}$ \\
\hline «Aunque es de noche» & 9 & $1(11,11 \%)$ & $7(77,78 \%)$ \\
\hline «Manantial de luz» & 15 & $7(46,67 \%)$ & $6(40 \%)$ \\
\hline «La tumba negra» & 1 & $1(100 \%)$ & - \\
\hline Total & 25 & $9(36 \%)$ & $13(52 \%)$ \\
\hline
\end{tabular}

Como punto final, la localización del poemario en TimeMapper (Tabla. 4), nos desvela que la poesía de colinas parece haberse vuelto más localista. Ya no se encuentran las numerosas referencias y poemas dedicados a ciudades italianas u otros espacios europeos, sino que opta por una fuerte 
focalización de su poesía dentro de la geografía española. De hecho, las únicas excepciones la conforman los poemas «Coyoacán» y «La tumba negra». Con ello, esta última etapa parece confluir en la búsqueda de un espacio vital, pleno y armonioso dentro de la propia cultura del poeta, del paisaje leonés «originario», así como de la isla y el mar ibicenco. Sin embargo, esta convergencia hacia lo propio no limita la sed del poeta pues, como demuestra «La tumba negra», su mundo crece y respira la vivencia de nuevas experiencias plausibles de ser poetizadas.

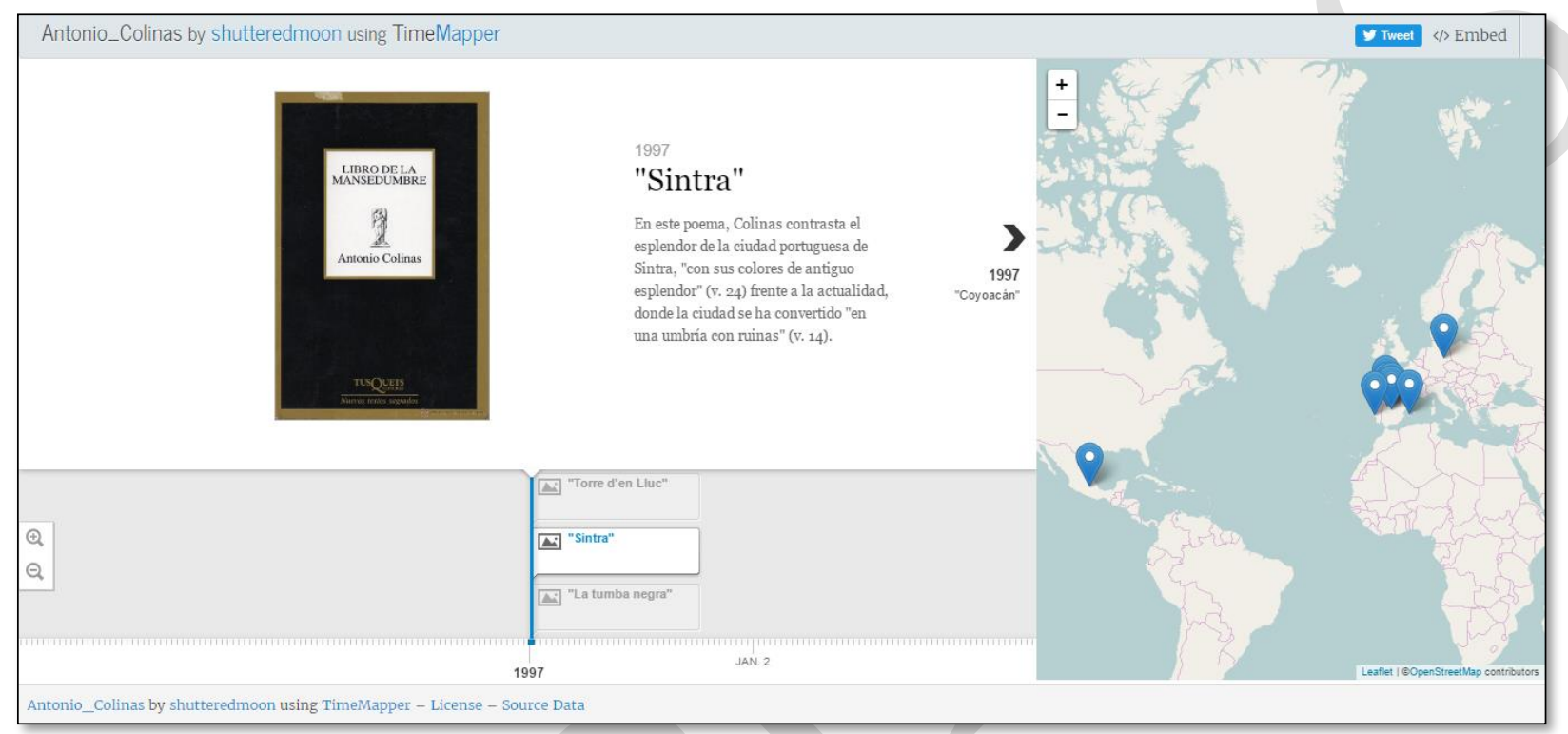

Fig. 4. Visualización con TimeMapper de las coordenadas geográficas en las que se inscribe el poemario Libro de la mansedumbre

\section{Conclusiones}

Habiendo analizado estos cuatro poemarios, podemos afirmar que la poesía de Antonio Colinas muestra un fuerte arraigo a la tierra, pero no tomada como una reivindicación de una tierra en particular, la suya, sino un espacio entendido como una serie de lugares que forman y construyen la experiencia vital de cada ser humano. Colinas refleja los suyos en sus poemas. Desde las raíces originarias del territorio leonés, pasando por la impresión del esplendor de la cultura italiana y la idílica belleza de la isla balear, todos sus cambios de residencia y viajes se convierten en el germen de una nueva etapa poética. Como señala Martínez García:

Porque, aunque poeta por vocación, Colinas no nació «aprendido». El compromiso vocacional se ha ido plasmando [...] en cinco elementos que, formulados geográficamente, fraguan el cemento- y el cimientofundamental de su poesía, siendo -a un tiempo-cantera de materiales y centro de su elaboración estética, sincronizada con los tramos de la personal andadura vital. A mi juicio, son estos: La Bañeza [...], Andalucía [...], Madrid [...], Italia [...], Ibiza. (Martínez García, 1990: 41).

Así, la poesía coliniana se fundamenta en el aditamento geográfico. En el primer poemario, el noroeste es el único eje espacial vertebrador que da sentido a su poética. Seguidamente, las localizaciones de Italia (Venecia, Florencia, Bérgamo, Paestum o el lago Trasimeno) se contraponen 
a lo ya conocido (Castra Petavonium, el monteTeleno, peña Trevinca...) en Sepulcro en Taqruinia, lo cual crea una poética espacial bipolar. Por el contrario, en Noche más allá de la noche añade las coordenadas ibicencas a la suma, haciendo que todo converja, de nuevo, hacia un único punto concéntrico: el Mediterráneo. Finalmente, en El libro de la mansedumbre, parece olvidarse de la atracción que ejerce el mundo grecolatino, por lo que la tendencia espacial fluye a la fusión del noroeste con la isla.

A grandes rasgos, también hemos comprobado cómo el tratamiento del espacio se va difuminando. Frente a la total concreción espacial en el primer poemario analizado, hemos identificado un descenso notable a lo largo de su trayectoria en el empleo de la toponimia. Esto parece obedecer al proceso de madurez del poeta, que le avoca a la universalización del tratamiento del espacio frente a la mayor tendencia del prurito culturalista de Sepulcro en Tarquinia o la limitación geográfica de Poemas de la tierra y la sangre. Así, podríamos identificar la primera etapa de Poemas de la tierra y la sangre por su tendencia al localismo; la segunda etapa, de Sepulcro en Tarquinia, por el culturalismo de un joven anonadado por la experiencia italiana; la tercera etapa, de Noche más allá de la noche, por un incipiente adulto abrumado por el mar como puerta a la reflexión y a la metafísica y, finalmente, la cuarta etapa de El libro de la mansedumbre se marca por la calma de un adulto pleno, que ama la naturaleza, que crece con ella. La visualización de esta evolución temporal y espacial es claramente visible gracias al etiquetado geoespacial realizado en http://timemapper.okfnlabs.org/shutteredmoon/ antoniocolinas.

Hemos explorado también el tratamiento de los ejes espacio-temporales en los poemarios. El tratamiento de este espacio se proyecta lingüísticamente a través del empleo de dos recursos fundamentales: los deícticos y los apóstrofes líricos, junto con el empleo de circunloquios en Noche más allá de la noche. Sin embargo, la incidencia de estos recursos también va decreciendo de forma paralela al empleo de la toponimia. Asimismo, en sus poemarios, se ha tendido hacia el juego con el espacio y con el tiempo, navegando entre su experiencia personal y los pasado míticos o históricos como localizaciones para expresar su propio microcosmos.

Concluimos sabiendo que no hemos agotado toda la potencialidad del análisis del tratamiento del espacio en la poesía de Antonio Colinas, así como las posibilidades que ofrece la herramienta TimeMapper. Sin embargo, esperamos haber abierto una puerta para el empleo de herramientas de geolocalización para el estudio de la literatura, incluso de obras poéticas y haber ofrecido una nueva visión de la obra poética de Antonio Colinas.

\section{Referencias bibliográficas}

Agustín Fernández, S. (2011). Poesía y pensamiento en Antonio Colinas, (1967-1988) (Ph.D. Thesis). Madrid, Universidad Complutense de Madrid; en http://www.tdx.cat/handle/10803/ $\underline{47440}$ (última consulta 3/12/ 2017).

Badía Fumaz, R. (2016a): Los ensayos literarios de Antonio Colinas. Pensando la creación desde el creador. Madrid, Verbum. 
(2016b): Las poéticas explícitas de Antonio Colinas (Ph.D. Thesis). Madrid, Universidad Complutense de Madrid; en http://www.tdx.cat/handle/10803/386711 (última consulta 3/12/ 2017).

Calleja Medel, G. (2003): Antonio Colinas, traductor. León, Universidad de León.

Colinas, A. (1969a): Poemas de la tierra y la sangre. León, Diputación Provincial. (1969b): Preludios a una noche total. Madrid, Rialp.

(1972). Truenos y flautas en un templo. San Sebastián/Donosti, Caja de Ahorros Provincial de Guipúzcoa.

- (1976): Sepulcro en Tarquinia. Barcelona, Lumen.

_ (1982): Noche más allá de la noche. Madrid, Visor.

- (1990): «El arte de escribir: mi experiencia personal (Autopercepción intelectual de un proceso histórico)», Anthropos, 105, pp. 20-38.

- (1997a): Córdoba adolescente. Córdoba, Los cuadernos de Sandua.

- (1997b): Libro de la mansedumbre. Barcelona, Tusquets.

- (2002): «Verdad y misterio en la palabra», Thélème. Revista Complutense de Estudios Franceses, 17, pp. 137-145.

- (2015): Preludios a una noche total. Madrid, Libros del Aire.

GALINA RuSSELl, I. (2011): «QQué son las humanidades digitales?», Revista Digital Universitaria, 12/7; en https://doi.org/http://www.ru.tic.unam.mx:8080/tic/handle/123456789/1904 (última consulta 3/5/2017).

GARcía MARTín, J. L., ed. (1996): Treinta años de poesía española (1975-1995). Sevilla, Renacimiento.

KÖBBEN, B. - BECKER, T. - BLOK, C. (2010): «TimeMapper - generating animated SVG from a WMS to visualise moving object data», en http://kartoweb.itc.nl/kobben/publications/2010/ W2GIS_TimeMapper_Kobben_Becker.pdf (última consulta 3/12/ 2017).

MARTí, M. (2016): «Peregrinos en la era Google. Herramientas de geolocalización y su aplicación al estudio de relatos de viajes medievales», Revista Luthor, VII/28; en http://www.revistaluthor. com.ar/spip.php?article144 (última consulta 3/12/ 2017).

Martínez Cantón, C. I. (2011): Métrica y poética de Antonio Colinas. Sevilla, Padilla Libros Editores y Libreros.

(2012): El ritmo como clave del verso en Antonio Colinas. Elementos rítmicos no métricos. León, Universidad de León.

- (2014): «La música en la poesía de Antonio Colinas», en F. AROCA, ed., Lire l'oeuvre poétique d'Antonio Colinas / Leer la obra poética de Antonio Colinas. Paris, Indigo-Université de Picardie, pp. 151-175.

MARTínez FERnÁndeZ, J. E. (2004): «Introducción a En la luz respirada», en A. ColinAs, En la luz respirada. Madrid, Cátedra. 
(2008): «Poética del cuadro ausente: poesía y pintura en Antonio Colinas», Signa: Revista de la Asociación Española de Semiótica, 17, pp. 225-248.

Martínez Fernández, J. E. - Martínez Cantón, C. I. (2017): «La experiencia del Museo en la poesía de Antonio Colinas», en J. E. MARTínez Fernández, El lienzo de la página. León, Universidad de León.

MARTínez GARCÍA, F. (1990): «Cuatro notas de invitación a la lectura de la obra poética de Antonio Colinas», Anthropos, 105, pp. 39-44.

PIATTI, B. (2012): «Vom Text zur Karte. Literaturkartographie als Ideengenerator», en C. REDER, Kartographisches Denken. Viena: Springer, pp. 269-279; en http://www.literaturatlas.eu/files/ 2012/08/kartographischesdenken.pdf (última consulta 3/12/2017).

Tadoun, G. M. N. (2009): Antonio Colinas o la escritura como aventura circular: poesía y transtextualidad desde su trilogía final (1992-2002). Salamanca, Universidad de Salamanca.

VILAS VIDAL, M. (1990): «Antonio Colinas frente al oboe de la creación», Anthropos, 105, p. 61. 